Öz

Bu çalıșma, endüstriyel tasarım

öğrencilerinin gözünden otomotiv

sektöründeki toplumsal cinsiyet ilişkilerini

araştırmaktadır. Son sınıf stüdyosunda

sanayiyle işbirliği içerisinde yürütülen iki

otomotiv projesi üzerinden yürütülen

çalışmanın amacı, öğrencilerin bu projelerle

edindikleri deneyimler ışığında, alanyazında

erkek egemen olduğu ve 'erkeğe uygun'

algılandığı belirtilen otomotiv sektöründe

kendilerine nasıl bir gelecek gördüklerini

anlamaktır. 20 kadın ve 11 erkek öğrenciyle

yapılan görüşmeler iki ana sorunun

çevresinde yürütüldü. İlk olarak, öğrencilerin

araç projesindeki deneyimlerine odaklanarak,

proje ekibinin kurulmasında, firmayla ve

diğer uzmanlarla ilişkilerde ve ekip içindeki

işbölümünde toplumsal cinsiyetin ne ölçüde

ve nasıl rol oynadığı soruldu. İkinci olarak,

öğrencilerin otomotiv sektörüne bakıș açıları

ve lisans eğitimi esnasında bir otomotiv

projesi yapmış olmanın bu bakış açısına

etkisi tartışıldı. Çalıșmanın bulguları,

endüstriyel tasarım öğrencilerinin bakış

açısından otomotiv sektörünün toplumsal

cinsiyetlendirilmesinin, bu sektörde ön plana

çıkan teknoloji ve teknolojinin asıl hakimi

olarak görülen mühendislerle ilişkiler

üzerinden gerçekleştiğini göstermektedir.

\section{Abstract}

This study explores gender relations in automotive design from the perspective of industrial design students. It draws on two

automotive projects carried out

collaboratively with industry in the final year

design studio, in order to understand how

industrial students, in light of their

experiences in these two projects, see

automotive industry, which is identified as

male-dominated and perceived to be

'suitable' for men, as an area they can work

in the future. Interviews were carried out

with 20 women and 11 men students around

two main questions. Focusing on the

experiences of students in the studio projects,

the first set of questions ask to what extent

and how gender had a role in setting up the

project team, in relations with the

collaborating firm and other experts

consulted during the projects, and in the

division of work within the team. Second set of questions investigated the perspectives of the students on automotive industry as well as the impact of carrying out an automotive design project during the undergraduate

education on this perspective. Findings show that according to industrial design students, automotive design is gendered through technology and the relationships with engineers, who are considered as the authentic experts on technology within this industry; and this view has a significant impact on the students' expectations from the automotive industry in relation to their future career prospects.

Anahtar Kelimeler:

endüstriyel tasarım, teknoloji, tasarım eğitimi, otomotiv tasarımı, toplumsal cinsiyet.

Keywords:

industrial design, technology, design education, automotive design, gender

\title{
Endüstriyel Tasarım öğrencilerinin Bakıs Açısından Otomotiv Endüstrisinin Teknik Bilgi ve Tasarımcı-Mühendis ilişkisi Üzerinden Toplumsal cinsiyetlendirilmesi
}

Plnar Kaygan

Orta Doğu Teknik Üniversitesi, Endüstri Ürünleri Tasarımı Bölümü

\section{Giriş}

Son birkaç on yıl, kadınların tasarımın teknolojiyle ve endüstriyel üretimle ilişkili alanlarında görünürlüğünü ve katılımını arttırmak için çeşitli girişimlere tanık oldu. Kadınların projelerini ön plana çıkarmayı hedefleyen yarışmalar, sergiler ve yayınlar hazırlandı (örneğin, Doering vd., 1994; Kirkham ve Walker, 2000; Martinez, 2007). Bu girişimlerin, kadınların tasarım alanındaki durumlarına mutlaka olumlu bir etkisi oldu. Ancak genellikle profesyonellere yönelik düzenlenen bu etkinliklere yön veren, kadın-erkek ikiliğinin temelindeki güç ilişkilerini sorgulayan eleştirel bakış açısının tasarım eğitiminde aynı derecede etkin olduğunu söyleyemeyiz.

Oysa sayıca az da olsa araştırmalarında toplumsal cinsiyet konusuna odaklanan eğitimcilerin tartışmalarına göre, tasarım alanlarındaki ayrışma lisans eğitimi esnasında başliyor ve hangi tasarım alanının hangi toplumsal cinsiyet için uygun olduğu varsayımları bu aşamada güçleniyor. Atölye kullanımı, üretim ortamı ve teknolojiyle ilişkili tasarım alanları kadın öğrenciler tarafından eril ve kendilerine mesafeli olarak değerlendiriliyor (Clegg ve Mayfield, 1999; Clegg vd., 1999). Özellikle otomotiv tasarımı, kadın öğrencilerin tereddütle yaklaştığı ve iş yaşamında kadınların çok küçük bir temsiliyete sahip olduğu sektör olarak tespit ediliyor (Hann, 1992; Kirkham ve Walker, 2000). Ancak öğrencilerle birebir görüşmelere dayalı araştırmalar gösteriyor ki bu mesafe ve tereddütü bireylerin kişisel tercih ve ilgi alanlarıyla açıklamak yetersiz (Kaygan, 2009). Bunun ötesinde, toplumsal yönlendirmeler ve kendilerine neyin ‘uygun' olup neyin olmadığı gerek meslek seçimi, gerekse bir mesleğin içerisinde hangi alana yönlenecekleri konusunda genç bireyler üzerinde çok etkili (Newman vd., 2004).

$\mathrm{Bu}$ çalışma, bahsi geçen tasarım ve toplumsal cinsiyet alanyazınına, endüstriyel tasarım öğrencilerinin gözünden otomotiv sektöründeki toplumsal cinsiyet ilişkilerini araştırarak katkıda bulunmaktadır. Son sınıf stüdyosunda sanayiyle işbirliği içerisinde yürütülen iki otomotiv projesine odaklanan çalışmanın amacı, öğrencilerin bu projelerle edindikleri deneyimler 1şı̆̆ında, alanyazında erkek egemen olduğu ve ‘erkeğe uygun' algilandiğ belirtilen otomotiv sektöründe kendilerine nasıl bir gelecek gördüklerini anlamaktır. Her ne kadar Türkiye'de kadın ve erkek endüstriyel tasarım mezunlarının sayısı arasında büyük bir fark olmasa da (Kaygan, 2014), öğrencilerin bakış açılarını anlamaya yönelik, bireysel anlatılara dayalı bir araştırma, bize uzaktan ve yalnızca rakamlara bakarak göremeyeceğimiz, 
toplumsal cinsiyete dayalı kaygıları, ayrışmaları ve beklentileri tespit etme olanağı sunmaktadır.

Türkiye'de tasarım alanyazını kadar teknoloji ve toplumsal cinsiyet alanyazınına da katkıda bulunmayı hedefleyen bu makale, öncelikle teknolojiyle olan ilişkilerine göre tasarım alanlarının nasıl cinsiyetlendirildiğini sunan bir tartışmayla başlamaktadır. Sonrasında, üzerinden veri toplanan iki otomotiv projesi tanıtılmakta; benimsenen yöntemsel yaklaşım ve araştırma tasarımı açıklanmaktadır. Görüşmelerde toplanan veriden tematik analiz yöntemiyle elde edilen bulguların sunulduğu kısmı takip eden son kısımda makalenin sonuçları gerek tasarım eğitimi gerek meslek bağlamında tartışılmaktadır.

\section{Tasarım alanlarının toplumsal cinsiyet süreçleri}

Toplumsal cinsiyet teorileri, toplumsal cinsiyetin (gender) biyolojik cinsiyetin (sex) aksine doğuştan gelen bir oluşum değil, sosyal yaşamda zaman içerisinde kurulan dinamik bir yapı olduğuna dikkat çeker. Simone de Beauvoir'ın 1949'dan bugüne değin sıkça hatırlatılan kısa ve öz ifadesinden hareketle, kadın (ya da erkek) doğulmaz, kadın (ya da erkek) olunur (de Beauvoir, [1949] 1988). Daha güncel teoriler bizi bu tanımın bir adım ötesine taşıyarak toplumsal cinsiyeti isimden ziyade bir eylem olarak ele alır (Butler, 1990; West ve Zimmerman, 1987). Bu yaklaşım, toplumsal cinsiyetin, kadın-erkek ikiliğindeki gibi ait olunan, sabit bir kategori değil; içinde yer aldığı bağlama, koşullara ve ilişkilere göre sürekli yeniden kurulan bir süreç olduğunu vurgular. Bireylerin cinsiyetlerine dair deneyimleri, yaşamları boyunca sahip oldukları farklı rollere, içinde yaşadıkları coğrafyaya ve zamana ve ait oldukları sosyal sınıfa göre çeşitlenmekte ve değişmektedir (Kimmel, 2000).

Dahası, toplumsal cinsiyet yalnızca insanlara özgü değildir; meslekler ve işler de cinsiyetlendirme süreçlerinden geçer (Britton, 2000). 1970'li y1llardan itibaren feminist sosyal bilimcilerin yürüttüğü araştırmaların kanıtladığı üzere, meslekler ve işler, geleneksel olarak bir kadının veya erkeğin sahip olması beklenen nitelik, beceri ve özelliklerle eşleştirilerek toplum tarafından cinsiyetlendirilir (Cockburn, 1983, 1988; Acker, 1990, 1992).

Tasarım pratiği de sosyal yaşamda var olan toplumsal cinsiyete dayalı bölünmelerle şekillenmiş, kimi alanlar kadınlar için kimileriyse erkekler için uygun olarak tanımlanmıştır (Attfield, 1989). Tasarım alanlarının cinsiyetlendirilmesinde teknolojiyle ve endüstriyel üretimle ilişkilerinin düzeyi belirleyici rol oynamıştır. Tasarım tarihçilerinin Batı Avrupa ve Kuzey Amerika odaklı analizlerine göre, kadınlar genellikle ev dekorasyonu, tekstil tasarımı ve takı tasarımı gibi geleneksel olarak kadının ilgi ve sorumluluk alanlarının uzantısı gibi görülen tasarım alanlarında yer almışlardır (Anscombe, 1984; Buckley, 1986, 1989; Sparke, 1995). Endüstriyel tasarım ve otomotiv tasarımıysa, teknoloji ve endüstriyel üretimle yakından ilintili diğer meslekler gibi (örneğin, mühendislik ve bilişim teknolojileri) erkeğe uygun algılanan, erkeklerin sayıca baskın olduğu ve kadınların kendilerine yer bulmakta zorlandığ tasarım alanları olarak kalmışlardır (Bruce, 1985; Bruce ve Lewis, 1990; Howard ve Setliff,

2000; Kirkham ve Walker, 2000).

Kadın ve erkeklerin farklı alanlarda yoğunlaşması anlamına gelen "yatay toplumsal cinsiyet ayrışması" (Hakim, 1996), yalnızca bireylerin tercih ve ilgi alanlarındaki farklılıklar olarak yorumlanmamalıdır. $\mathrm{Bu}$ ayrışma, keskin güç dengesizliklerini de beraberinde getirmektedir: Teknolojiyle ilişkili ve geleneksel olarak erkek egemen alanlar tasarımcılara çok daha iyi kariyer olanakları sağlamaktadır. Örneğin, Clegg ve diğerleri (1999) otomotiv tasarımının, tasarım mesleklerinin zirvesinde yer aldığginı belirtir.

Mevcut alanyazında kadının teknolojiyle ilişkili tasarım mesleklerindeki durumuna dair iki ana yaklaşım tespit ediyoruz (Kaygan, 2016). Tasarım tarihi alanında yoğunlaşan ilk yaklaşım, bu mesleklerde tasarım pratiğine katkıda bulunmuş ancak yazılı tasarım tarihinde ismi geçmeyen kadın tasarımcıları ortaya çıkarıp görünür kılmak. Diğer yaklaşımsa, bir pazarlama 
stratejisi olarak kadın tasarımcıların kadın kullanıcıların istek ve ihtiyaçlarını daha iyi anlayıp yanıtlayacağı iddiasını savunmak. Arkasına endüstrinin de desteğini alan ikinci yaklaşım, kadın temsiliyetinin çok düşük olduğu otomotiv sektöründe kimi işverenleri kadın tasarımcıları özellikle işe almaya teşvik etmiş gibi görünüyor. Biri 1950'lerden diğeriyse 2000'lerin başından iki vaka, yalnızca kadınlardan oluşan tasarım ekiplerinin bu amaçla nasıl kurulduğunu ve tanıtımının yapıldığını net bir şekilde örneklemektedir.

Birincisi, 1950'lerde Amerika'da General Motors'un “Tasarımın Genç Kızları” (Damsels of Design) ismiyle basına tanıttığ tasarım ekibi. Tümü kadınlardan oluşan bu ekip, kadın kullanıcıların ihtiyaçlarına yönelik, ancak otomobilin iç tasarımında renk, doku ve kumaş seçimiyle kısıtlı çözümler geliştirmeleri için bir pazarlama stratejisi olarak kurulmuş (Kirkham ve Walker, 2000; Howard ve Setliff, 2000). Aradan yarım asır geçtikten sonra, 2004 yılında, bir başka otomotiv firması olan Volvo'nun "Senin Konsept Araban" (Your Concept Car) projesinde benzer bir girişim görüyoruz. Basın açıklamasında verilen bilgiye göre dokuz kadından oluşan proje ekibinin dördü tasarımla ilgili görevlerden sorumlu (Volvo, 2004).

Aradan geçen on yılların iş yaşamında toplumsal cinsiyet konusunda getirdiği hassasiyet ve değişim sonucunda olsa gerek, bu örnekte kadınların tıpkı erkekler gibi herkes için tasarım yapabileceği ve otomobilin içi kadar dışını tasarlamaya da yetkin oldukları vurgulanıyor. Yine de eşitlikçi bir bakış açısından bu uygulamanın tatmin edici bulunmaması için iki neden var. Birincisi, gerek firmanın basın açıklaması gerek konuyla ilgili haberler kadınların otomobil tasarlamasının olağan bir durum olmadığı ve ancak kadın kullanıcıyla ilişkili özel bir projeyle gerçekleşebileceği mesajını veriyor (bknz. Volvo, 2004). İkincisi, nasil ki General Motors örneğinde kadın tasarımcılar yalnızca otomobilin içiyle ilgileniyorsa, Volvo örneğinde de kadınlar üretime geçmesi planlanmayan konsept bir otomobil üzerinde çalışıyorlar. Dolayısıyla kadınlardan oluşan tasarım ekibinin bir pazarlama stratejisi olmanın da ötesinde, 'gerçek' bir tasarım ekibi olarak kurulduğunu söylemek zor. Dahası, Schwarzman ve Decker'ın (2008) analizine göre bu proje, otomobili eve ait aktiviteler üzerinden tanımlayan bir terminoloji kullanarak hem kadın tasarımcıyı hem de kadın kullanıcıyı 'evcilleştirme' ve kadın için uygun rolün eve ve evhalkına bakmak olduğunu tekrarlama yatkınlığı taşımaktadır.

Sythre ve diğerlerinin (2005) makalesi de benzer bulgular sunuyor. Yazarlara göre, her ne kadar firma, kadın tasarımciları güçlü kılmak ve kadınların da en az erkekler kadar başarılı otomotiv tasarımcıları olduğu mesajını vermek istese de projenin medyadaki haberleri, kadın ve erkek tasarımcıları ve kullanıcıları geleneksel toplumsal cinsiyet ikilikleri üzerinden kıyaslamakta. Örneğin, erkek tasarımcı ve kullanıcıların aracın teknolojik özelliklerine, kadın tasarımcı ve kullanıcılarınsa aracın çocukları etkileyebilecek havalandırma kalitesi gibi özelliklerine dikkat ettiği yazılmıştır.

Bu iki vakanın tartışması dışında otomotiv tasarımı ve toplumsal cinsiyet alanyazını ne yazık ki çok sınırlı. Aşağıda tanıtılan iki proje üzerinden yürütülen bu araştırma, tasarım öğrencilerinin kişisel deneyimlerini ve otomotiv sektörüne dair algılarını inceleyerek alanyazındaki tartışmaları genişletmeyi hedeflemektedir.

\section{İki araç projesi: Kazıcı yükleyici ve itfaiye aract}

Bu çalışmada Endüstri Ürünleri Tasarımı Bölümü dördüncü sınıf stüdyosunda farklı senelerde yürütülen iki eğitim projesi ele alınmaktadır. 2013-2014 akademik yılında yürütülen kazıc1-yükleyici için kabin tasarımı konulu ilk projede, 19'u kadın ve 18'i erkek 37 öğrenci, dokuz ekip halinde çalıştı. Projede öğrencilerden beklenen, çift yönlü aracı kullanan operatörün karşılaştığ1 yön değişimine uyum sağlama problemini ele alarak kazıcı-yükleyici kabininin içini yeniden tasarlamaktı. 
İkinci olarak, 2015-2016 akademik yılında yürütülen, itfaiye için araç üstü ekipmanları konulu projede, 20'si kadın ve 10'u erkek 30 öğrenci yedi ekip halinde çalıştı. Öğrencilerden, aracın kullanıcısı olan itfaiyecilerin sorumluluklarını ve görevlerini, itfaiye birimleri içindeki iş bölümünü ve müdahale işlemlerinin sırasını ve itfaiyecilerin sundukları hizmetteki çeşitliliği göz önünde bulundurarak özelleşmiş bir müdahale görevi için tasarım önerileri geliştirmeleri istendi. Örneğin, bir ekip su alt1 arama-kurtarma ekiplerine odaklanırken, bir diğer ekip endüstriyel bölgelere yönelik müdahale araçlarıyla ilgilenmeyi seçti.

Tasarım iş tanımı birbirinden çok farklı olan bu iki eğitim projesinin, bu araştırma için temel bir ortak noktası vardı. Her iki proje de otomotiv sektöründen bir firmayla işbirliği içerisinde kurgulandı ve yürütüldü. Firmalardaki tasarımla ilgilenen ekiplerin toplumsal cinsiyet dağılımı, alanyazını destekler nitelikteydi. İlk projeye çeşitli aşamalarda ve farklı yoğunluklarda destek veren dört tasarımc firma temsilcisinin bir tanesi kadındı. Ekipten bir erkek tasarımcı, proje boyunca sık sık öğretim üyeleriyle birlikte kritiklere katılıp öğrencilere geribildirim verdi. İkinci projede proje boyunca düzenli olarak destek veren ve yine kritiklere gelerek öğrencileri yönlendiren bir mühendis firma temsilcisi vardı. Hem bu kişi hem de bir jüriye katılıp projelere geribildirim sağlayan diğer iki mühendis erkekti. Dolayısıyla bu projeler aracılığıyla öğrenciler otomotivle, daha çok erkeklerin yer aldığı bir sektör olarak tanıştılar.

Araştırma için veri, bu makalenin yazarı tarafından, projeler tamamlandıktan sonra öğrencilerle yapılan görüşmelerle toplandı. İlk projenin görüşmeleri henüz öğrenciler mezun olmadan yapıldığı için proje ekipleriyle odak gruplar düzenlenebildi. Davete olumlu yanit veren dört ekipten sekizi kadın ve sekizi erkek 16 kişiyle görüşüldü. İkinci projeye ait veri, öğrenciler mezun olduktan sonra toplandığ 1 için ekipleri bir araya getirmek mümkün olmadığından öğrencilerle bireysel görüşmeler yapıldı.
Her ekipten en az iki kişi olmak üzere, 12'si kadın ve üçü erkek toplam 15 öğrenci görüşmelere katıld1.

Görüşmeler, iki ana soru çevresinde yürütüldü. İlk olarak, öğrencilerin araç projesindeki deneyimlerine odaklanıldı. Proje ekibinin kurulmasında, firmayla ve diğer uzmanlarla ilişkilerde ve ekip içindeki işbölümünde toplumsal cinsiyetin ne ölçüde ve nasıl rol oynadığı soruldu. İkinci olarak, öğrencilerin otomotiv sektörüne bakış açıları ve lisans eğitimi esnasında bir otomotiv projesi yapmış olmanın bu bakış açısına etkisi tartışıldı.

Görüşmelerde alınan ses kayıtları yazıya aktarılarak tematik nitel analize hazır hale getirildi. Görüşme kayıtları "açık kodlama" yöntemiyle satır satır kodlanarak bir kod listesi oluşturuldu (Rubin ve Rubin, 2005). Bulguların sunulduğu aşağıdaki kısımda bulguları hem örneklendirmek hem de kanıtlamak için öğrencilerin anlatılarından alıntılar kullanıldı.

\section{Görüş̧melerin analizi}

Analizden elde edilen bulgular, öğrencilerin büyük bir kısmının otomotiv sektörüne dair net fikirleri olduğunu gösteriyor. Makalenin önceki kısımlarında bahsedilen mevcut alanyazına paralel olarak, çalışmanın bulgularında da otomotiv endüstrisi, tasarımcıların istihdam edildiği diğer endüstriyel sektörlere göre teknolojiyle ve özellikle makine mühendisliğiyle daha yakın ilişkileri olan bir alan olarak tanımlandı. Genel kanı, otomotiv sektöründe çalışmanın (1) gerekli teknik bilgiye sahip ya da en azından ilgi duyuyor olmayı ve (2) mühendislerle yakın ilişkiler içerisinde çalışmayı göze almayı gerektirdiği yönünde. Gerek sektöre dair bakış açılarını gerekse stüdyo projesindeki deneyimlerini paylaşırken öğrencilerin toplumsal cinsiyet anlatıları bu iki konu etrafında yoğunlaştı.

\section{Teknik bilginin ve otomotive ilginin önemi}

Projelerin ilk gününde öğrenciler ekiplerini kurdular. Öğrenciler ekiplerini belirlerken daha önceki projelerde birlikte çalıştıkları ve yakın arkadaşları olarak 
tanımladıkları kişileri tercih ettiklerini belirttiler. Dolayısıyla her iki projede de ekipler proje konusundan bağımsız bir şekilde oluşturulmuş. Ancak öğrencilerin anlatılarından, ekipte "otomotivden anlayan" öğrencilerin olmasının getirdiği avantajların, proje başladıktan sonra fark edildiğini ve tartışıldığını anlıyoruz. "Otomotivden anlayan", yani arabayla erken yaşta tanışan ve yalnızca tasarımcı olarak değil, kullanıcı olarak da otomotive ilgi duyan ve bir hobi olarak zaman ayıran kişilerin gerek bu projelerde gerekse otomotiv sektöründe daha başarılı olacağ 1 inancı öğrenciler arasında paylaşılıyordu:

Ben de farkl sektörlerde çalışmak isterim. Ama bu sektör bana çok küçüklügünden otomotiv sektöründe hayali olan ve hayatı boyunca bunu bir tutkuya dönüştüren insanlar varmış, onların arasında çok güçsüz kalacakmışım gibi hissettiriyor. (Öğrenci 31, kadın)

Öğrencilerin çoğuna göre araç projelerinin gerektirdiği teknik bilginin kendisi de, bu bilgiye ulaşmanın yolları da daha önceki projelerde olduğundan karmaşıktı. Bir öğrenci, aynı dönem yaptıkları mobilya projesiyle kıyaslayarak araç projesinin zorluğunu şöyle anlattı:

Mesela şey kolaydl, mobilya projesinde bağlantı elemanlarlyla ilgili teknik eksikliğim vard, onu hocalarıma sorarak, işte kataloglara bakarak ya da makalelerle çok kolay çözebildim. Ama bu projede, özellikle akstaki yük dengesinde mesela, benim için bu kadar kolay olmadi. (Öğrenci 18, kadın)

Özellikle sürücü ehliyeti olmayan ve otomotivle ilgili terimlere yabanc1 öğrenciler, çalışmaya öncelikle ilgili terimleri ve araç parçalarının isimlerini öğrenerek başladıklarını anlattılar. Kadın öğrencilerin büyük bir kısmı, bu projede önceki stüdyo projelerine göre ilk kez kendilerini bazı erkek meslektaşlarından daha az bilgili ve dezavantajlı hissettiklerini belirttiler. Tamamı kadın öğrencilerden oluşan bir ekibin üyesinden yapılan alıntı bu bulguyu örneklendiriyor:
Illk düşündüğ̈̈müz şey şuydu. Biz grup olarak dört kizdan oluşuyorduk. Ve hani hepimizin oturup gerçekten "bu araba neymiş, ne yaplyoruz, neresini modifiye ediyoruz, aslinda ne yapmaya çalışlyoruz”, böyle oturup her şeyden, projenin ilk başında tasarımından önce bir arabayı anlamak gibi bir çabamız oldu. (Öğrenci 28, kadin)

Ancak bu varsayıma sahip öğrenciler, bu farklılığın biyolojik kökenli doğal bir ayrışmanın değil sosyal yaşamda kendilerine öğretilen rollerin ve sunulan ilgi alanlarının bir sonucu olduğunun altını çizdiler. Aşağıdaki alıntıda, bir başka ekipten, ekibin dördüncü üyesinin erkek olmasını özellikle tercih ettiklerini belirten bir kadın öğrenci, bu varsayımı çocukluktan itibaren öğretilen geleneksel toplumsal cinsiyet rolleriyle açıkliyor:

Üç kız bütün gün şu olur mu bu olur mu, o özelliklerin de ne olduğunu araştırdık. Çünkü ne olduğunu bilmiyoruz. Zaten ilk bize gelen anlatan bey, onun şeyiyle öğrenmiştik, işte şaft nedir, yok diferansiyel ne, nasil etkili olduğunu. Ama erkekler bunu zaten biliyorlardl. Bunu bilmelerinde de küçüklükten beri aslında bize oynatılan oyuncaklarla bile etkili olduğunu düşünüyorum.

(Ö̈rrenci 29, kadın)

Benzer şekilde, bir başka kadın öğrenci, sinifta otomotiv konusunda teknik bilgisiyle öne çıkan bir erkek öğrenciyle kendisini kıyaslayarak bu farklılığın aile içerisinde çocuklukta yapılan yönlendirmelerle şekillendiğini iddia etti:

Onun bu konuda bir bilgi birikimi olduğu için zaten eskiden beri, büyürken ailesinde bile. Bir şekilde ilgisi o yönde olduğu için bu konuda bilgi birikimi çok fazla oluyor. Ben heyecan verici olduğunu düsünmeme rağmen bu konuda ayrıca bir araştırma yapmadı̆̆ım için, oturup geceleri "Hangi arabayı alsam?", "Oğlum şu araba da çok hızlı", diye bakmadığım için böyle bir bilgi birikimim yok. (Öğrenci 19, kadın)

Her ne kadar kendi dezavantajlı durumlarını dile getirmek için kendilerini erkek 
öğrencilerle kıyaslasalar da, kadın öğrenciler teknik bilgiye olan mesafe farklılıklarını genelgeçer bir kadın-erkek ikiliğine indirgememeye özen gösterdiler. Tüm erkeklerin otomotivle aynı düzeyde ilgili olmadığını, sınıfta sadece birkaç kişinin teknik bilgisiyle güçlü olduğu, onların da yukarıda anlatılan nedenlerle erkekler arasından çıktığını düşündüklerinin altını çizdiler.

Özellikle otomotive ilgisi olduğunu belirten iki erkek öğrenci dışında görüşülen diğer erkek öğrenciler de teknik bilgi konusunda sınıf arkadaşlarından farklı bir durumda olmadıklarını dile getirdiler:
Araştırmacı: Ekipteki tek erkek olmak sana ekstra bir sorumluluk ya da farklı bir rol getirdi mi sence?
Öğrenci 22 (erkek): Şey anlamında çok farkl bir rol getirmedi, zaten ben de mesela şey değilim; o işte arabalarla ilgilenen, bölüme ben araba tasa- rımcisı olacağım diye gelen erkekten değilim. O yüzden aslında çok da farklı değildi benim getirdiğim bakış açısı.

Bu erkek öğrencilerin anlatılarında da benzer şekilde otomotivden anlayan ve heyecan duyan erkek öğrenciler ayrı bir grup olarak tanımlanıyordu. Ancak sebebini bilgi eksikliği olarak görmeseler de, bu öğrenciler de kadın sınıf arkadaşlarının gerek projede gerekse genel olarak otomotiv sektöründe kendilerine kıyasla dezavantajlı olduğunu belirttiler. Onlara göre, kadınların tasarımcı olarak bilgi ve becerilerinde erkeklerden bir farkl111kları yok, ancak otomotiv sektörünün erkek egemen ortamında kendi mesleklerinin içinde kadınlarla çalışmaya alışkın olmayan erkek mühendisler, kadın tasarımcılarla iletişim kurmakta gönülsüz davraniyor ya da zorlaniyor. Bu durumun, kadınlar için otomotiv sektörünü endişe verici ve caydırıcı hale getirdiğini düşünüyorlar.

Özellikle projenin ilk haftalarında kendini bilgisiz ve ne kadar araştırırsa araştırsın hiç öğrenemeyecekmiş gibi hissetmek bazı kadın öğrencilerin ortak endişesi olmuş. Otomotiv konusunda teknik bilgiye sahip olmamak kadar bu bilgi eksikliğinin başkaları tarafindan anlaşıllyor olması endişesi kadın öğrenciler tarafından dile getirilen bir başka kaygı oldu:
Birçok insan yani araba kullanan insanlar çok daha rahatlar otomotivle ilgili konuşurken. Mesela benim için dev bir kara delikti orast. Dolaylslyla böyle o temel terimleri anlayana kadar bile bir süre kendi kendime ekstra araştırma yapmam gerekti. O sırada dlşarlya bir şekilde çok fazla neyi ne kadar bilmediğimi çok belli etmemeye çalıştım, çünkü zaten öyle bir önyargı var, hani bir de onu güçlendirecek bir şey... (Öğrenci 8, kadin)

Projenin ilk haftalarındaki bu olumsuz hislere rağmen, kadın öğrencilerın büyük bir kısmı bu konudaki bilgi eksiklerinin giderilemez olduğunu ya da erkek meslektaşlarına göre sürekli dezavantajlı bir durumda olduklarını düşünmediklerinin altını çizdiler. Tersine, proje başladıktan ve öğrenciler araçla ve teknik detaylarla ilgili araştırmalar yürüttükçe baştaki endişelerinin azaldığını, özgüvenlerinin arttığını ifade ettiler. "Otomotivden anlayan" iki erkek sınıf arkadaşının aracın yük dağılımıyla ilgili hesaplamaları nasıl yaptıklarını izleyen bir kadın öğrenci gözlemlerini şu şekilde anlatıyor:
Benim gözümde büyüttüğüm şeyler... Belki de çok basit, benim de yapabile- ceğim bir şeyi, onların [bu kadar hizll] yapması beni şaşırtmıştı. O kadar aslında, gerçekten basit fiziği kullana- rak yaptılar. Ăgırlıklarını giriyorsun internette yazlyorsun çıklyor ve işte momentum allyor, bir şey yapıyor. Ama ben mesela orada korkmuştum, gözüm korkmuştu diyebilirim. (Öğrenci 20, kadin)

$\mathrm{Bu}$ öğrencilere göre asıl önemli problem, bilgi eksikliğinin ve bu eksikliğin neden olduğu özgüvensizliğin getirdiğ zaman kaybı. Projenin takviminin çok sıkışık olduğu düşünüldüğünde bazı sınıf arkadaşlarına göre projede kat etmeleri gereken yolun daha uzun olduğunu düşünmek, endişelerinin temel sebebi olmuş. Ancak terminolojiyi, aracın yapısını ve 
üretim sürecini öğrendikten sonra, bir tasarımcı olarak gerçek hareket alanları olarak tanımladıkları senaryo, ergonomi, kullanıcı araştırması ve malzeme üzerinde çalışırken bu endișelerinin ortadan kaybolduğunu belirttiler:

Öğrenci 1 (kadın): Biz araştırma konusunda pozitif geribildirim almıştık. Rengine, dokusuna ve malzemenin pozitif deneyime etkisi... Biz aslında tamamen onu nasıl sağlayacă̆ımıza odaklandik. O nedenle cinsiyetten dolayı sürekli bir kaybımız olmadl. Zaten sürecin içine girince...

Öğrenci 2 (kadin): ... o tamamen kayboldu, kendiliğinden kayboldu aslında, korkumuz da gitti.

Yürüttükleri stüdyo projesindeki deneyimlerinin öğrencilerin otomotiv sektörüne dair bakış açılarını nasıl etkilediği sorusunun yanıtları analiz edilirken, profesyonel yaşamda teknik bilgi ve otomotive duyulan kişisel ilginin öneminin aynı derecede vurgulanmadığ 1 saptandı. Kadın ve erkek öğrencilerin neredeyse tümü endüstride, "gerçek" otomotiv projelerinde teknik bilginin tasarımcılardansa mühendislerin uzmanlık alanında kalacağını, o nedenle otomotiv sektöründe çalışan bir endüstriyel tasarımcının karşısına çıkacak esas zorluğun, teknik bilgiye sahip olmak değil, teknik bilginin uzmanı olan mühendislerle birlikte çalışmak olduğunu belirttiler.

\section{Mühendislerle birlikte çalışmak}

Öğrencilerin mühendislerle çalışma deneyimleri bu projelerle sınırlı değildi. Stajlardaki deneyimlerine ve mühendislik okuyan arkadaşlarına da sıklıkla referans verdiler. Yukarıdaki kısımda yeri geldikçe değinildiği gibi, sektördeki mühendislerle yaşanması beklenen ilişkilerin, öğrencilerin otomotiv sektöründe tasarımcı olarak çalışmaya dair fikirleri üzerinde belirleyici etkisi olduğu tespit edildi. Öğrencilere göre, otomotiv sektörü mühendislerin baskın olduğu ve yönlendirdiği bir sektör olarak tasarımcılara kısitlı imkanlar sunuyor. Sektörün, özellikle Türkiye'deki haliyle, öğrenciler arasında paylaşılan bir imajı var: Problemlerinde kullanıcı değil teknoloji ve teknik bilgi odaklı, mühendis egemen ve tasarımciya yeterince alan açmayan. Bir erkek öğrenci otomotiv sektörünü nasıl gördüğünü şöyle anlatıyor:

Çok aynı geliyor bana aslinda, yapılabilecek şeyleri çok kısıtllymış gibi geliyor. Ve daha çok tasarım gerektiren değil de hani mühendislik ürünü şeyler... Dış stili, kabuğu dışında endüstriyel tasarımcının katkısının çok olabileceğini düşünmediğim bir alan. (...) Çok kısıtll, katı kuralları var ve onun dışına asla çıkamayacakmışsınız gibi. Ve otomotiv sektöründe çalışırsam bütün gün bilgisayar başında oturup hiçbir gözlem yapamayacă̆ım, araştırma yapamayacakmışım gibi geliyor. Yani bilmiyorum, belki insan etkileșimi bile olmayacakmıș gibi geldiğinden... (Öğrenci 21, erkek)

Görüşmede sorulan sorulardan biri eğitim esnasında bir otomotiv projesi yapmış olmanın bu sektör hakkında öğrencilerin fikirlerini etkileyip etkilemediğini anlamaya yönelikti. Bu soruya öğrencilerin yarısından fazlası, olumlu şekilde etkilediği yanıtını verdi. Projenin öncesinde sektörü korkutucu bulan öğrenciler bu projeyle birlikte tasarımcının bu sektörde nasıl çalışabileceğini hayal edebilir hale geldiklerini söylediler. Özellikle araç iç tasarımında kullanıcı odaklı problemlerin tespitinin ve çözümünün; ergonomi, stil ve malzeme çalışmanın tasarımcının severek yapmak isteyeceği işler olduğunu belirttiler. Buna rağmen, mevcut gözlemleriyle mühendis ve mühendislik egemen bu sektörde kendilerini dezavantajlı durumda bulacaklarında hemfikir oldukları söylenebilir.

Mühendislerle birlikte çalışırken yaşadıkları veya yaşamayı bekledikleri problemleri anlatırken, toplumsal cinsiyet ve mesleğin iç içe geçtiğini, hatta bazen birbirinin yerini aldığını görüyoruz.

Araç seçiminde falan, özellikle yük taşıma kapasitesi olsun bu tarz şeyleri ögrenmek için hangisinin daha uygun olduğunu bilemediğimizden ötürü [otomotiv sektöründe çalıştığını bildiğimiz 
tanıdı̆̆ımız mühendislere] danıştık. $O$ insanlar daha çok bilmediğimizi düşünüp... Gerçekten bilmiyoruz, bilmek de istiyoruz ama sanki ögrrenemeyeceğimizi çok da karışmamamız gerektiğini hissetmistim, öyle söyleyeyim. (Öğrenci 31, kadin)

Bu alıntının sahibi kadın öğrenci mühendislerle olan bu deneyimini bir kadın olarak mı yoksa tasarımcı olarak mı yaşadığını ayırt edemediğini belirtti; şöyle devam etti:

Bu bölümle de alakalı biraz. Açıç̧ası [şimdi çalıştığım] şirkette de yaşadım bunu. (Gülïyor) Biraz dedikodu gibi olacak ama... Mühendis olmayana, mühendislik okumayana daha farkl baklyorlar, sanki daha az bilgili gibi baklyorlar. (Öğrenci 31, kadın)

Bir başka kadın öğrenciye göre, benzer şekilde, otomotiv sektöründe tatmin edici bir şekilde yer alamayacağını düşünmesinin nedeni, mühendislerin, hem kadın hem de tasarımcı olarak kendisinin teknik bilgisine olan çifte güvensizliği. Yukarıdaki alıntıda olduğu gibi, bu öğrenci de çalışmakta olduğu firmadaki mühendislere referansla neden böyle düşündüğünü anlatiyor:

Aslinda biz tasarım olarak... Klzerkekten ziyade, tasarımcilar olarak giremiyoruz galiba. Çünkü bunu ben şeyde de karşılaşstım. Bizim buradaki fabrikada sonuçta mobilya üretiyorlar. Ve mobilya tasarımı da sonuçta tasarımcıların çok fazla yaptığ şey. Ama mesela bir mekanik bir şeyi tasarlama, o detay tasarlamaya geldiği zaman hemen mühendisler geliyor, "Siz bilmezsiniz, bir dakika, biz yapacağız" falan. Aslinda niye bilmeyelim. Yani sonuçta biz de saylsal bölümden geldik. Hani belki de bunları biz de şey yapmıyoruz, ben de "Hayır yapabilirim, bir dakika" diye kendime güvenip de atlayamıyorum aslında. Hani o belki de o güvensizliğin üstüne bir de cinsiyet gibi bir şey binince, zaten kiz ne anlar gibi bir şey binince, bu sefer iyice "Tamam siz yapın, ben sadece kenarına köşesine fillet atacağım" gibi bir şeye girmek zorunda kaliyoruz. (Öğrenci 23, kadin)

Görüşmelerden çıkan sonuçlara göre, mühendisin sahip olduğu teknik bilginin sembolik üstünlüğü yalnız otomotiv sektöründe değil, mühendisle işbirliği gerektiren pek çok sektörde, bu iki meslek grubu arasında güç dengesizliğine neden oluyor. Her ne kadar bu güç dengesizliğinin hem kadın hem de erkek tasarımcılar için olumsuz sonuçları olsa da kadınlar için gerek mühendisliğin gerekse teknik bilginin erkekle eşleştiriliyor olması çifte sorun olarak tanımlanıyor. Bu sorun, özellikle tasarımcı ve mühendisin birebir etkileşiminde görünürlük kazanıyor. Örneğin, bir ekibin tek erkek üyesi, projeye yönelik sorularını danıştıkları toplantıda mühendisin sürekli kendisiyle göz teması kurarak konuştuğunu ve bu durumun toplantıdan sonra ekip içerisinde konuşulduğunu anlattı.

Bugün artık bağımsız bir araştırma alanı olan feminist teknoloji çalışmaları, mühendislik mesleğinin tarihsel olarak nasıl eril ve erkeğe uygun bir meslek olarak kurulduğunu göstermektedir (Wajcman, 2010). Son on yılda sayısı artan, çeşitli sektör ve iş yeri bağlamında mühendislerin kişisel deneyimleri üzerinden yürütülen araştırmalar, mesleğin kalıplaşmış eril kültürü içerisinde yer almak isteyen kadınların yaşadığı zorlukları ve bu zorluklarla baş etme yöntemlerini belgelemektedir (Dryburgh, 1999; Miller, 2004). Eril bir tavir takınarak kadınlığını arka plana itmeye çalışmak, bu çalışmalarda sıklıkla vurgulanan yöntemlerden biri (Demaiter ve Adams, 2009; Peterson, 2010; Powell vd., 2009).

Benzer şekilde, bu çalışmanın bulguları da eril bir meslek kültürüne mensup mühendislerle ve diğer teknik elemanlarla olumlu iletişim kurabilmeyi sağlayan belirli bir üsluba işaret ediyor. Öğrencilere göre, resmi olmayan bir dil kullanmak, böylece samimi ama aynı zamanda hiyerarşik bir ilişki kurmak yukarda bahsedilen ileişim zorluklarının üstesinden gelmek için iyi bir yöntem. Özellikle "abi” diye hitap edebiliyor olmanın önemi gerek projenin ortağı olan firmadan projeye destek olan 
mühendisle gerekse öğrencilerin kişisel olarak danıştıkları mühendislerle ilişkilerinde gözlemlenmiş:

Firmayla yapılan görüşmelerde, oradaki yetkili kişiyle konuşuyoruz. Mesela erkeklerin daha yoğun olduğu gruplar hemen böyle bir işte, "abi, görüşelim abi, size bir şey soracağız", falan... Çünkü böyle erkek erkeğe konuşmanin da bir jargonu var ya, yani onları çok daha rahat bir şekilde kullanıp, nasıl diyeyim, çok daha kısa sürede daha yakın bir ilişki kurabildiler. Hani bizim için, işte, "Filanca bey, sizinle görüşebilir miyiz", falan, böyle çok daha şey kurumsal bir tavırda oldu. (Öğrenci 19, kadın)

Bu öğrenci, ekibin "abi” diye hitap etmenin önemi kavradığı halde bunu yapabilecek bir erkek üye barındırmadığını, o nedenle bahsettikleri firma temsilcisiyle hep mesafeli bir ilişkileri olduğunu anlattı. Üç erkek ve iki kadın öğrenciden oluşan bir ekiple yapılan odak grup görüşmesindeyse öğrenciler ekipten bir erkeğin bu dile hakim olduğunu, o nedenle teknik elemanlarla yapılan görüşmelerde onu ön plana çıkardıklarını anlattılar:

Öğrenci 9 (erkek): Genel olarak onu öne çıkarma gibi bir tavır vardı bence grup içinde.

Araştırmacı: Neden?

Öğrenci 9 (erkek): O mesela "nasılsınız abi?" diye girince...

Öğrenci 10 (erkek): Benim hiç yapamayacağım bir şey, ama o yapabiliyordu.

Öğrenci 9 (erkek): Biraz abi kardeș gibi daha samimi selamlașmalar, konușmalar..

Ancak eril olarak tanımlanan bu yaklaşım, her erkek öğrenci tarafından benimsemezken, kendini gerektiğinde daha eril davranabilir olarak tanımlayan bir kadın öğrenci tarafından iyi bir strateji olarak anlatıld1:

O tür ortamlarda zaten șu an benim [çalıştığım] şirkette de yaptığım bir durum; "abi" olayına bağllyorum direkt. Hani bey mey değil, abi, $k i$ samimi olsun ama aynı zamanda abi olsun falan diye böyle. Direkt "abi"ye bağlamıştık orada [bir ekip arkadaşım] ile ikimiz. O tür sorular sormuştuk. (Öğrenci 17, kadin)

Sonuç olarak, resmi olmayan ve aynı zamanda mühendise teknik bilginin uzmanlığını teslim eden, bu mütevazi eril tavır, kimi öğrencilere zorlandıkları kişisel ilişkilerde iyi bir baş etme yöntemi olarak hizmet ederken, kendini bu iletişim biçimiyle rahat edecek kadar eril bulmayan öğrencilerin geri planda kalmayı tercih etmelerine neden olmuş gibi görünüyor.

\section{Tartıșma}

Mühendislik, pek çok ülkede olduğu gibi, Türkiye'de de saygınlığı kabul görmüş bir meslek (Küskü vd., 2005; Pehlivanlı Kadayıfçı, 2015). Özellikle erkeklerin yüksek temsiliyet gösterdikleri endüstriyel üretim ve fabrika ortamıyla yakından ilişkili, makine, elektrik elektronik ve inşaat mühendisliği gibi alanlar, 'gerçek' mühendislik alanları olarak nitelendirilerek üyelerine daha çok saygınlık kazandırmakta (Zengin, 2010). Yukarıda sunulan bulgular, endüstriyel tasarım öğrencilerinin bakış açısından otomotiv sektörünün toplumsal cinsiyetlendirilmesinin, bu sektörde ön plana çıan teknik bilgi ve teknik bilgiye sahip olan makine mühendisleriyle ilişkiler üzerinden gerçekleştiğine işaret etti. Öğrencilerin anlatıları mevcut alanyazındaki tartışmalara paralel: Bir tasarım alanının teknoloji ve endüstriyel üretimle ilişkisi ne kadar güçlüyse, kadınlar o alanı kendilerine o kadar mesafeli görüyorlar ve kariyer seçimlerinde o alana tereddütle yaklaşıyorlar.

Ancak kadın öğrencilerin, eğitim projesi ve mesleki kariyer bağlamında otomotiv sektörüne yaklaşımları birbirinden farklı. Kısıtll bir takvim çerçevesinde tamamlanması gereken ve tasarımcılardan oluşan bir ekiple yürütülen bir eğitim projesinde kadın öğrencilerin öncelikli kaygısı olası teknik bilgi eksiklikleri. Kendilerini erkek sınıf arkadaşlarıyla kıyaslayarak, geleneksel olarak yönlendirilmedikleri bir alana 
dair gerekli teknik bilgiye ve terminolojiye hakim olma konusunda dezavantajlı buluyorlar. Ancak bu kaygı, projenin birkaç haftasından sonra kazanılan özgüven ve edinilen teknik bilgiyle ortadan kalkıyor. Bu kaygının ortadan kalkmasının bir nedeni de öğrencilerin proje boyunca çeşitli aşamalarda aldıkları notlarla, yani projedeki başarılarıyla, toplumsal cinsiyet arasında bir ilişkisi olmadığını farketmeleri olabilir.

Öğrencilerin otomotiv sektöründe tasarımcı olarak çalışmaya dair fikirleriyse teknik bilgidense, bu sektörde yakın çalışmaları gereken mühendislerle yaşanması beklenen ilişkilerle şekilleniyor. Hem erkek hem de kadın öğrenciler arasında ortak görüş Türkiye'de otomotiv sektörünün kullanıcı değil teknoloji ve teknik bilgi odakl1, mühendis egemen ve tasarımcıya yeterince alan açmayan bir sektör olduğu yönünde. Mühendislik odaklı, tek tip teknolojinin ve teknik bilginin değerli olduğu bir sektörde tasarımcının uzmanlık alanına giren senaryo, ergonomi, kullanıcı araştırması ve malzeme gibi konulara yeterince önem verilmeyeceği kaygısını taşıyorlar.

Otomotiv sektörüne dair bu görüşler, mühendisin uzmanlığıyla tasarımcının uzmanlığ 1 arasındaki güç dengesizliğine işaret ediyor. Alanyazında mevcut çalışmalarda da tespit edilen bu güç dengesizliği, mesleki bilgi, beceri ve yetkinlikleri teknolojiye göre konumlandırarak kurulan bir ikilikle kuruluyor. Bu ikilik içerisinde mühendislik tarafına düşen teknoloji, tasarım tarafına düşen estetik, ergonomi ve kullanıcı gibi kavramlara göre daha temel, daha değerli, daha fazla profesyonel bilgi, beceri ve yetkinlik gerektirir olarak görülüyor ve diğerinden üstün tutuluyor (Peterson 2007, Attfield, 1989; Kaygan, 2014). Bu hiyerarşik ikiliğin vurgulandığ 1 (özellikle mühendislerin yönetim kademelerinde sayıca fazla olduğu) kurumsal bağlamlarda, tasarımcıların mühendislerle olan ilişkisi bir 'kendini ve mesleğini kanıtlama' mücadelesi içeriyor. Öğrencilerin anlatılarında gördüğümüz gibi, bu dezavantajlı durum hem kadın hem de erkekler tarafından fark ediliyor. Ancak bu ikilikte kadın öğren- ciler, erkek egemen bir mesleki kültürden gelen mühendislerle olan ilişkilerinde kendilerini teknik bilgi, beceri ve yetkinliklere sahip profesyoneller olarak kabul ettirmekte bir kez kadın bir kez de tasarımcı oldukları için erkek tasarımcılara göre daha fazla zorlanmayı bekliyorlar. $\mathrm{Bu}$ açıdan bakıldığında, kadın öğrencilerin disiplinler arası ilişkilere dair sahip oldukları kendini kanttlama ve gerektiğinde eril bir duruş sergileyebilme konusundaki endişeleri, mesleğinde azınlık olan kadın mühendislerin yaşadıklarıyla önemli benzerlik gösteriyor (Hatmaker, 2013; Miller, 2004).

Burada şunun altını çizmek gerekir ki teker teker baktığımızda kadın tasarımcıların her erkek mühendisle yukarıda anlatılan sorunları yaşayacağını iddia etmek doğru olmaz. Kadın tasarımcıların mühendislerle problemsiz çalıştı̆̆ pek çok örneğin de bulunduğuna inanıyorum. Burda dile getirilen sorunun kaynağı, mühendisliğin tarihsel olarak değişime dirençli eril kültürü.

\section{Sonuc}

$\mathrm{Bu}$ tartışmadan endüstriyel tasarım eğitimine yönelik iki önemli çıkarım yapabilir. Birincisi, lisans eğitiminde pek çok endüstriyel sektörde kaçınılmaz olan tasarımcı-mühendis işbirliğini desteklemeye yönelik stratejiler geliştirilmeli. Profesyonellerin gerek kendi mesleklerine gerekse diğer mesleklere dair fikir ve önyargıları henüz lisans eğitimi esnasında oluşmaya başliyor (Dryburgh, 1999). Itkonen ve diğerlerine (2009) göre, lisans eğitimi esnasında disiplinler arası işbirliği yapmamış tasarımcı ve mühendisler, bunu ilk kez çalışma yaşamında deneyimlediklerinde zorluklar yaşıyorlar. Oysa kendi uzmanlık alanının gerektirdiği bilgi, beceri ve yeterliklerin yanı sıra profesyonel yaşamda yakın ilişki içerisinde olacağı mesleklerin bakış açısını tanıyan öğrenciler, ekip çalışmalarında çıkabilecek çatışmalara, çeşitli bakış açılarını ve öncelikleri anlamaya hazırlıklı olabiliyorlar (Kaygan ve Demir, 2017). Tasarım lisans programlarında, disiplinler arası tasarım projeleri yürütülebilecek derslerle tasarım ve mühendislik öğren-

14 Sayı 25, Mayıs 2018 
cilerinin arasındaki etkileşimi arttırmak ve birbirlerinin bakıș açılarını öğrenebilecekleri bir zemin sağlamak makalede tespit edilen problemlerin çözümüne katkı sağlayabilir.

İkincisi, her ne kadar bu projeleri yürütmüş olmak öğrencilerin otomotiv sektörüne girme konusundaki eğilimlerini önemli derecede etkilemis gibi görünmese de, çalışmanın bulguları gösterdi ki, projenin öncesinde sektörü korkutucu bulan kadın öğrenciler bu projeyle birlikte bu sektörde nasıl çalışabileceğini hayal edebilir hale geldiler. Bu çalışmada olduğu gibi, kadın öğrencilerin sayıca fazla olduğu endüstriyel tasarım bölümlerinde stüdyo eğitiminde otomotiv projelerine yer vermek, öğrencilerin bu geleneksel olarak kadınların uzak durduğu sektörle tanışmalarında ve sektörü kendi bakıș açılarından değerlendirmelerinde etkili olacaktır. Özellikle kadın mühendis ve tasarımcıların dahil edildiği üniversite-sanayi işbirliği projeleri, kadın öğrencilere rol model sağlayarak özgüven geliştirmelerinde destek olabilir.

\section{Teşekkür}

Araştırmaya katılarak benimle deneyimlerini paylaşan tüm öğrencilerimize samimiyetleri ve açık yüreklilikleri için teşekkür ederim. Stüdyo ekibinde yer aldığım bu iki otomotiv projesinde işbirliği yaptığımız, öğrencilerimiz arasında hiçbir ayrımcılık yapmadan teknik destek veren ve öğrencilerimizin otomotiv sektörüyle tanışmasını sağlayan firma temsilcilerine sürece katkıları için teșekkür ederim. Her ne kadar bu makalede sunulan araștırma ve onun kapsamında yapılan görüşmeler makalenin yazarı tarafindan yapıldıysa da, bu projelerin ilki dokuz, ikincisi sekiz kişilik stüdyo ekipleriyle yürütülmüştür. $\mathrm{Bu}$ ekiplerde yer alan, projeleri birlikte hazırlayıp yürüttüğümüz stüdyo ekibi üyelerine projelere katkılarından dolayı teşekkür ederim•

\section{Kaynakça}

Acker, J. 1990. Hierarchies, Jobs, Bodies: A Theory of Gendered Organizations. Gender and Society 4 (2), s. 139-158

Acker, J. 1992. Gendered Institutions: From Sex Roles to Gendered Institutions. Contemporary Sociology 21 (5), s. 565-569.

Anscombe, I. 1984. A Woman's Touch: Women in Design from 1860 to the Present Day. Londra: Virago.

Attfield, J. 1989. Form/Female Follows Function/Male: Feminist Critiques of Design. İçinde: Walker, A J. der. Design History and the History of Design. Londra: Pluto Press, s. 199-225.

Britton, D. M. 2000. The Epistemology of the Gendered Organization. Gender and Society 14 (3), s. 418-434.

Bruce, M. 1985. A Missing Link: Women and Industrial Designer. Design Studies 6 (3), s. 150-156.

Bruce, M. ve Lewis, J. 1990. Women Designers - Is There a Gender Trap? Design Studies 11 (2), s. 114-120.

Buckley, C. 1986. Made in Patriarchy: Toward a Feminist Analysis of Women and Design. Design Issues 3, s. 3-14.

Buckley, C. 1989. 'The Noblesse of the Banks': Craft Hierarchies, Gender Divisions, and the Roles of Women Paintresses and Designers in the British Pottery Industry 1890-1939. Journal of Design History 2 (4), s. 257-273.

Butler, J. 1990. Gender Trouble. New York: Routledge.

Clegg, S. 1999. Disciplinary Discourses: A Case Study of Gender in Information Technology and Design Courses. Gender and Education 11 (1), s. 43-55.

Clegg, S. ve Mayfield, W. 1999. Gendered by Design: How Women's Place in Design is Still Defined by Gender. Design Issues 15 (3), s. 3-16.

Cockburn, C. 1983. Brothers: Male Dominance and Technological Change. Londra: Pluto Press.

Cockburn, C. 1988. The Gendering of Jobs: Workplace Relations and the Reproduction of Sex Segregation. Walby, S. der. Gender Segregation at Work. Milton Keynes: Open University Press, s. $29-42$.

de Beauvoir, S. ([1949] 1988). The Second Sex. (Çeviri ve editör H. M. Parshley) Londra: Pan Books.

Demaiter, E. I. ve Adams, T. L. 2009. 'I really didn't have any problems with the male-female thing until...': Successful women's experiences in IT organizations. Canadian Journal of Sociology 34 (1), s. 31-53.

Doering, E., Switzky, R. ve Welz, R. 1994. Goddess in the Details: Product Design by Women. New York: Association of Women Industrial Designers.

Dryburgh, H. 1999. Work Hard, Play Hard: Women and Professionalization in Engineering - Adapting to the Culture. Gender and Society $13(5), \mathrm{s}$. 664-682.

Hakim, C. 1996. Key Issues in Women's Work: Female Heterogeneity and the Polarisation of Women's Employment. Londra: Athlone.

Hann, J. 1992. Women in Transport Design. Women in Management Review 7 (2), https://doi. org/10.1108/09649429210010887

Hatmaker, D. M. 2013. Engineering Identity: Gender and Professional Identity Negotiation among Women Engineers. Gender, Work and Organization 20 (4), s. 382-396.

Howard, E. ve Setliff, E. 2000. In 'A Man's World': Women 
Industrial Designers. İçinde: Kirkham, P. der. Women Designers in the USA 1900-2000: Diversity and Difference. New Haven, CT: Yale University Press, s. 269-290.

Kaygan, P. ve Demir, Ö. 2017. Learning about Others: Developing an Interdisciplinary Approach in Design Education. İçinde: Bohemia, E., de Bont, C. ve Holm, L. S. der. Conference Proceedings of the Design Management Academy. London: Design Management Academy, s. 1595-1611.

Itkonen, M., Ekman, K. E. ve Kojo, I. 2009. Murjottelu - Interdisciplinary Training Campaign for Industrial Design and Engineering Students. European Journal of Engineering Education 34 (3), s. 263-271.

Kaygan, P. 2009. Boys Design Cars and Girls Design Dolls? A Case Study on Occupational Segregation in Industrial Design. Design Principles and Practices: An International Journal 3 (3), s. 153-164.

Kaygan, P. 2014. 'Arty' versus 'Real' Work: Gendered Relations between Industrial Designers and Engineers in Interdisciplinary Work Settings. The Design Journal 17 (1), s. 73-90.

Kaygan, P. 2016. Gender, Technology and the Designer's Work: A Feminist Review. Design and Culture 8 (2), s. 235-252.

Kimmel, M. S. 2000. The Gendered Society. İkinci Bask1. New York: Oxford University Press.

Kirkham, P. ve Walker, L. 2000. Women Designers in the USA 1900-2000: Diversity and Difference. İçinde: Kirkham, P. der. Women Designers in the USA 1900-2000: Diversity and Difference. New Haven, CT: Yale University Press, s. 49-84.

Küskü, F., Özbilgin, M. ve Özkale, L. 2007. Against the Tide: Gendered Prejudice and Disadvantage in Engineering. Gender, Work and Organization 14 (2), s. 109-129.

Martínez, J. G. 2007. Women Only: Design Events Restricted to Female Designers during the 1990s. Design Issues 23 (2), s. 17-30.

Miller, G. E. 2004. Frontier Masculinity in the Oil Industry: The Experience of Women Engineers. Gender, Work and Organization 11 (1), s. 47-73.

Newman, C., Bauer, M., Agogino, A. M. ve Mankoff, J. 2004. Perceptions of the Design Process: An Examination of Gendered Aspects of New Product Development. International Journal of Engineering Education 20 (2), s. 452-460.

Pehlivanlı Kadayıfçı, E. 2015. Gendered Engineering Culture in Turkey: Construction and Transformation, Yayımlanmamış Doktora Tezi, Orta Doğu Teknik Üniversitesi, Ankara.

Peterson, H. 2007. Gendered Work Ideals in Swedish IT Firms: Valued and not Valued Workers. Gender, Work and Organization 14 (4), s. 333-348.

Peterson, H. 2010. The Gendered Construction of Technical Self-Confidence: Women's Negotiated Positions in Male-dominated Work Settings. International Journal of Gender, Science and Technology 2 (1), s. $65-88$.

Powell, A., Bagilhole, B. ve Dainty, A. 2009. How Women Engineers Do and Undo Gender: Consequences for Gender Equality. Gender, Work and Organization 16 (4), s. 411-428.

Rubin, H. J. ve Rubin, I. S. 2005. Qualitative Interviewing - The Art of Hearing Data. Thousand Oaks, Londra, New York: Sage.
Schwartzman, R. ve Decker, M. 2008. A Car of Her Own: Volvo's 'Your Concept Car' as a Vehicle for Feminism? Studies in Popular Culture 30 (2), s. 100-118.

Sparke, P. 1995. As Long as it's Pink: Sexual Politics of Taste. Londra: Pandora.

Styhre, A., Backman, M. ve Börjesson, S. 2005. The Gendered Machine: Concept Car Development at Volvo Car Corporation. Gender, Work and Organization 12 (6), s. 551-571.

Volvo. (2004). Volvo Your Concept Car (YCC) Press Release [çevrimiçi]. Erișim yeri: www.volvoclub. org.uk/press/pdf/presskits/YCCPressKit.pdf [Erişim tarihi: 9 Temmuz 2017].

Wajcman, J. 2010. Feminist Theories of Technology. Cambridge Journal of Economics 34 (1), s. 143-152.

West, C. ve Zimmerman, D. H. 1987. Doing Gender. Gender and Society 1 (2), s. 125-151.

Zengin, B. 2010. Women Engineers in Turkey: Gender, Technology, Education and Professional Life. LAP Lambert Academic Publishing. 